\title{
Benjamin o el primado de la política sobre la historia
}

\author{
M. REYES MATE \\ Instituto de Filosofia del CSIC
}

Tres cuestiones se investigan en el presente trabajo. En primer lugar, lo que tiene que ver el concepto benjaminiano de historia con el de filosofía de la historia, dominante en Europa. Si este último puede ser caracterizado como una ontología del presente, Benjamin subraya que sólo cabe un futuro nuevo si se quiebra el presente. En segundo lugar, el concepto de pasado capaz de romper el presente e inaugurar un futuro real. El pasado en cuestión, inédito y salvador, es el de los vencidos. Finalmente, qué política es esa que Benjamin coloca por encima de la historia. Extrapolando a Benjamin cabría enfrentar una universalidad negativa a la tuiversalidad positiva. La segunda es siempre particular, la primera conlleva un orden mundial basado en la intersubjetividad asimétrica.

Quien se enfrente al pensamiento benjaminiano tiene que sortear una triple dificultad: la indeterminación de los textos que obliga a coleccionar formulaciones comparables que ayuden a hacerse una idea siempre aproximada del pensamiento; el recurso estratégico a imágentes para explicar el nudo gordiano de una reflexión, lo que predispone a todo tipo de interpretaciones; y el hermetismo del lenguaje como si el sentido jamás pudiera ser totalmente entregado a la comprensión del intérprete, como si el lenguaje tuviera que atender tanto a desvelar el significado como a velarle.

Además de estas dificultades semánticas hay otra que brota de la misma benjaminiana manera de ser, que proviene, pues, del propio contenido del pensamiento benjaminiano. Si se dice que la imagen del pasado wamenaza desaparecer con cada presente que no se reconozca en ella», ${ }^{1}$ esto es, si se está convencido de que el pasado sólo existe en cuanto recordado, se puede entender entonces la obra del intérprete en sentido redentor. Interpretar a Benjamin es salvarle no sólo del olvido sino para el presente. Importaría entonces menos la fidelidad a los textos cuanto la captación de su chispa inédita con la que iluminar nuestro presente. Así, según Susan Bucks-Morss, entendió Adorno la interpretación del amigo. La Memoria deviene Aufhebung, en el triple sentido de conservar un modelo de pensamiento, de negar como definitivo su versión particular, para poder ofrecer finalmente una visión nueva, superadora de lo que fue en sus inicios. ${ }^{2}$ En este caso la interpretación de 
Benjamin se hace desde su particular manera de entender el recuerdo, que no es mimesis sino creación.

También cabe otra posibilidad: dar por buena y universalmente válida la hermenéutica benjaminiana de su tiempo. Como si viviéramos en el mismo tiempo, con las mismas desazones, las mismas angustias y desesperanzas y buscáramos en él las claves para nuestro tiempo. Sacaríamos entonces del pensamiento benjaminiano una herméneutica del peligro. Hoy como ayer vivimos la misma falta de perspectiva política, la misma incapacidad del sujeto para tomar las riendas del destino, las mismas amenazas de destrucción planetaria. Benjamin es entonces un punto de referencia porque intentó dar una respuesta cultural y política en un momento de máxima desesperación. El tratado entre Hitler y Stalin cerraba toda respuesta al fascismo desde la izquierda; la organización de la represión nacionalsocialista agravaba más que aliviaba toda forma de resistencia; los hombres interiorizaron la opresión exterior como autoaniquilación de la conciencia; se pretendió no sólo aniquilar a un pueblo sino que se consiguió no dejar huellas de las víctimas más extremas. $^{3}$ Si en un contexto tan extremo alguien fue capaz de fundar la esperanza y de plantear una respuesta política a su tiempo, ese tal debe servir de modelo a un tiempo como el nuestro que se caracterizaría por los mismos síntomas, aunque de otra manera. Esa sería la herméutica del peligro, un planteamiento del pensamiento benjaminiano capaz de hacernos ver el peligro de los tiempos que corren.

Si la primera modalidad de interpretación pone el acento en el talante (la palabra «sistema» estaría aquí fuera de contexto) del pensamiento benjaminiano, la segunda se fija en los contenidos. Para optar por la segunda habría que presumir una continuidad entre los tiempos de Walter Benjamin y los nuestros, una presunción difícil de mantener no sea más que porque al menos políticamente el fascismo perdió la guerra; recientes acontecimientos tales como el derrumbe del socialismo real pone sordina a la confianza benjaminiana en el materialismo histórico, en tanto que un hecho como la guerra del Golfo da a los problemas políticos contemporáneos una nueva dimensión mundial. Más accesible parece el camino de Adorno, aunque, a diferencia de él, la realidad política tenga que estar más presente en la memoria filosófica.

Aquí nos vamos a ocupar de su filosofía de la historia. Ese núcleo de su pensamiento va a servirnos de base, en el doble sentido de fundamento y lugar logístico, de todas nuestras reflexiones. Sus breves e intensas reflexiones, conocidas como «tesis sobre filosofía de la historia» concentrarán las referencias del presente escrito.

Benjamin era muy consciente de la novedad de su planteamiento; hablaba incluso de un giro copernicano en la consideración de la historia. La novedad se cifraba en lo siguiente: "hasta ahora se tomaba al pasado 
como punto fijo y se pensaba que el presente tenía que esforzarse para que el conocimiento se asiera a ese sólido punto de referencia. Ahora, sin embargo, esa relación debe cambiar en el sentido de que el pasado se convierte en envite dialéctico, en acontecimiento de la conciencia despierta. La política ostenta el primado sobre la historia. Los hechos son algo que nos golpea; asirles es tarea de la memoria. El modelo de la memoria es el despertar: una experiencia en la que nos gozamos con el recuerdo de lo familiar, de lo ordinario, de lo que más nos importa. Lo que Proust significaba con los cambios que sufren los muebles de una habitación semioscura en el momento del despertar, lo que Bloch entiende por lo oscuro del instante vivido, todo eso es lo mismo que hay que asegurar aquí, en el ámbito de lo histórico y colectivo. Existe un todavía-no-saber consciente del pasado cuya exigencia tiene la estructura de un despertar».4 Aquí están dibujados, en filigrana, los momentos cruciales de su idea de la historia. En primer lugar, la autonomía del pasado. El pasado no es un punto fijo a disposición de un conocimiento riguroso y sediento de hacerse con toda la realidad, incluyendo la que ha sido. El pasado tiene vida propia, sorprende a la conciencia presente, toma la iniciativa. No se capta ese pasado, en segundo lugar, por la ciencia, por la reconstrucción cientifica, sino mediante el recuerdo; un recuerdo que nos adviene a la consciencia con la novedad con que se hacen presentes a la consciencia semidormida los muebles de un cuarto oscuro en el momento de la vigilia. Finalmente, el primado de la política sobre la historia. Lo histórico, el pasado, no interesa como reconstrucción, sino como construcción. ${ }^{5} \mathrm{El}$ acento está puesto en el presente. La atención al pasado no está dirigida por un interés arqueológico sino para incidir en el presente. Por eso es político.

Para entender esta pretendida originalidad en el tratamiento de la historia debemos desarrollar la respuesta a estas tres preguntas: I) ¿cómo entienden las filosofías clásicas de la historia el pasado?; II) ¿qué pasado es ése, capaz de irrumpir en el presente?; III) ¿de qué política se trata cuando se la pasa el testigo privilegiado que ha ostentado la historia?

\section{Por una nueva filosofía de la historia}

Benjamin toma distancias tanto respecto a filosofias de la historia en las que el logro de la felicidad ocurre fuera de la historia humana, como respecto a aquellas otras en las que la misma historia es salvífica. Es decir se opone a teologias de la historia y a sus versiones secularizadas. Que en las primeras se hable de salvación y en las segundas de progreso, no debe ocultar la íntima cercanía.

Para san Agustín, en efecto, el estado de gracia se reserva a la civitas dei. Es ahí donde tiene lugar la salvación. La civitas terrena sólo participa de ello cuando rompe las ataduras con su propia historia y se disuel- 
ve en la historia sagrada. La historia de los hombres alcanza su sentido gracias a un mecanismo que él no controla, que les es dado.

Otro tanto ocurre con las filosofías modernas de la historia. Tomemos, por ejemplo a Kant. Kant parte del hecho que los acontecimientos históricos son acciones humanas; como tales no son el resultado de reacciones instintivas y por ende no pueden explicarse mediante una sistematización causalista. Pero tampoco vale una sistematización teleológica ya que las acciones carecen en su conjunto de un plan, carecen del telos que el hombre pudiera darse a sí mismo. La única salida sería «una sistematización objetivo-teleológica, es decir, una interpretación del plexo de los acontecimientos que provenga de una finalidad determinante ínsita en la estructura de los acontecimientos y por tanto objetiva, es decir, independiente de las intenciones subjetivas de los hombres».6 El modelo referencial de esta teoría sería la vieja Historia Sagrada, con la diferencia de que si allá los acontecimientos tienen que encuadrarse en el plan divino, acá, en la historia secularizada de Kant, tienen que someterse a una polisémica "intencionalidad de la naturaleza» (Naturabsicht).?

Pues bien, Benjamin no acepta ni un esquema en el que la historia de los hombres es el lugar de la infelicidad, quedando la felicidad reservada a lo extrahistórico hasta el punto de que sólo la teología pueda entender de progreso, ni tampoco fetichiza una concepción en la que el progreso de la historia hacia su realización sea tan de este mundo que hasta puede prescindir del Menschenabsicht o voluntad humana, ${ }^{8}$ una constante ésta no sólo en Kant sino en toda la filosofía de la historia idealista y postidealista.

El punto de vista de Benjamin era, más sencillamente, el de que toda verdad es histórica aunque no toda la historia es verdadera. El hombre se juega su destino en el tiempo pero la verdad de ese destino no se puede identificar con el proceso real de la historia. ${ }^{9}$

Hay, pues, un evidente sentido polémico en sus tesis sobre filosofía de la historia. La polémica apunta a un doble destinatario: las teorias del progreso y el historicismo.

\section{Las teorías del progreso}

De ellas se ocupan explícitamente las Tesis IX-XII. En la DX recurre, como en él es habitual, a una imagen para señalar su pensamiento. Si recordamos que estas "tesis», destinadas a constituir el prólogo a su gran obra -Das Passagen-Werk - son el resultado de veinte años de reflexión, habrá que convenir la importancia de cada detalle, incluso a sabiendas de que estos papeles no fueran considerados como definitivamente acabados. ${ }^{10}$ Benjamin habla del «ángel de la historia», una extraña figura ya que los ángeles de Yahvé son mensajeros de Dios o de los hombres, pero no de 
la historia. Lo que primero llama la atención es la oposición entre lo que el ángel ve y lo que nosotros vemos. Son dos visiones distintas del mismo objeto: lo que el ángel ve como desastre nosotros lo vemos como progreso. El montón de escombros que jalonan su marcha es lo que los humanos celebran como historia de progreso. Benjamin, sin embargo, no se sitúa del lado del ángel sino con el nosotros. La respuesta a los problemas de la historia tiene que hacerse desde la cultura, desde la construcción humana, y no desde el ángel que es incapaz de dar una respuesta al desastre que ve pues quisiera "detenerse, despertar a los muertos y recomponer lo despezado", pero sin lograrlo. Es impotente ante el huracán "que nosotros llamamos progreso». Si nos fijamos bien, el ángel de la historia quiere volar contra ese viento huracanado. Aquí hay un sutil juego de relaciones. El ángel de la historia vuela contracorriente de lo que nosotros entendemos por historia, esto es, progreso, que para él no es tal, sino desastre. Pero ¿cuál es la historia de la que ángel es mensajero? La Biblia sólo conoce el pasado: lo que queda atrás es lo que simultáneamente está delante de la vista. El futuro es lo que está de espaldas. Su progreso está detrás.

Decíamos que el punto de vista de Benjamin no era el del ángel; por otro lado, tampoco está dispuesto a hacer suya la historia como progreso. ¿Cómo sale Benjamin de este dilema? Preguntémonos por qué trae aquí a colación al ángel. Lógicamente para hacemos ver la naturaleza catastrófica de una filosofía de la historia que acepta resignadamente el costo humano del progreso. Y para algo más: para hacer presente una manera original de entender el progreso desde las esperanzas conservadas en el pasado. Es la tradición que representa el ángel lo que es importante aunque no pueda aceptar la interpretación que hace el ángel de la misma. Aquí se apunta una de las constantes en el planteamiento benjaminiano: el sentido hay que buscarlo en la tradiciones religiosas, pero ya no nos está permitido interpretarlas teológicamente, sino profanamente, como crítica de las ideologías presentes y como quiebra del poder del presente.

El interés político queda patente en las tres Tesis siguientes. Hay que prevenir a los contemporáneos de los peligros del mundo, denunciar las pompas y vanidades de quienes se ofrecen como salvadores cuando no tienen más que traiciones e incompetencias sobre sus conciencias. Son esos políticos de izquierdas que se jactan de unas masas ciegas, sometidas a aparatos burocráticos gracias a una fuerte dosis de confianza en el progreso. Con dichas ideas "pretenden liberar a la criatura política de las redes con que la han embaucadon." No es tanto que se trate de explicar u organizar a la historia desde la categoría de progreso cuanto que se recurra al progreso para ocultar su fracaso y para reproducirle. Este afán de hacer del hombre un progresista, que interiorice la teoría del progreso y se convierta en agente del mismo, esa pretensión ética soterrada en las teorías del progreso, eso es lo que no le parece de reci- 
bo. No es, pues, que Benjamin esté contra el progreso sino, como dirá Adorno, "contra la confusión entre progreso y humanidad". ${ }^{12}$ Mientras la humanidad sea el telos del progreso, nada que objetar. El problema empieza cuando cambian las tornas y es el progreso el objetivo de la humanidad. Tal es nuestro caso, de ahí que sólo se puede hablar con rigor del progreso en tanto en cuanto se aboga por su liquidación.

En la tesis siguiente, Tesis XI, Benjamin pone nombre y apellidos a los políticos y a las políticas que se han erigido en ideología de la izquieda. Habla de la socialdemocracia y sentencia: «nada ha corrompido tanto a los obreros alemanes como la opinión de que nadan a favor de la corrientes. Las interpretaciones deterministas del materialismo histórico, echando sobre extrañas leyes de la naturaleza la responsabilidad de sujetos históricos, eso ha hecho más daño que todas las armas del enemigo de clase. También se cita a Joseph Dietzgen, el obrero ideólogo del movimiento obrero, para quien "el salvador del tiempo nuevo se llama trabajo». Calvino venía en ayuda de un movimiento obrero más sensible a las promesas salvíficas del desarrollo de las fuerzas productivas que a las obligaciones que exigía un coherente desarrollo de las relaciones de producción. Benjamin lamenta que el movimiento prefirirá escuchar a Calvino más que a Marx. Porque Benjamin se empeña sistemáticamente en salvar a Marx. ${ }^{13}$ Extraño, como que aquí se empecine con la socialdemocracia y deje fuera al leninismo...

El problema que plantea pues la teoría del progreso, en general, y de la socialdemocracia, en particular, es el del sujeto de la historia. En la literatura marxista se habla del sujeto de la historia como sujeto de la revolución. Para Benjamin, como para Marx, el sujeto de la historia es «la clase que lucha», pero mientras éste se refiere al sujeto del cambio revolucionario, aquél señala que lo que le preocupa es «el sujeto del conocimiento histórico». Las diferencias se prolongan en otro punto más: mientras que los modernos políticos de izquierda se entretienen en asignar a las clase obrera kel papel de redentora de generaciones futuras», a êl, sin embargo, lo que le interesa es lo mismo que a Marx, esto es, ver a la clase obrera como el sujeto de la liberación final "en nombre de generaciones vencidas». ${ }^{14}$

El sujeto de la historia no hay que verlo en función del futuro sino del pasado, no pensando en la felicidad de nuestros herederos sino en los sufrimientos de nuestros antepasados. Sólo entonces podremos entender la historia.

La clave del conocimiento de la historia está en el pasado y no en el futuro. La razón está en que el conocimiento histórico tiene que ser simultáneamente un conocimiento de sí mismo. La novedad que conlleva el descubrimiento de la realidad presente del sujeto sólo es posible desde un «sujeto beligerante» que niega su realidad sabida. La iluminación de la realidad, más allá de lo que hasta ese momento es evidente, brota del pasado, es un Erinnerungsbild que no trae el sujeto voluntariamente a la 
conciencia sino que salta del pasado hasta una conciencia wen momento de peligron, es decir, necesitada de conocimiento.

Ahora empiezan a encajar las piezas. Cuando Benjamin dice que el sujeto no puede ser la humanidad o un sujeto transcendental, sino «la luchadora clase oprimida en su situación más extrema» ${ }^{15}$ está señalando la naturaleza práctica y no teórica de su teoría del conocimiento. Cuando escribe uque la verdad no es una función temporal del conocimiento sino que brota de un núcleo temporal que se esconde tanto en el conocido como en el cognoscentem, ${ }^{16}$ Benjamin se sale de la lógica marxista que hace del conocimiento un momento de poder del sujeto cognoscente, para posibilitar un conocimiento no como poder sino como liberación. $\mathrm{La}$ inseguridad en que este planteamiento coloca al sujeto que no puede conocerse más que en la medida en que es informado por el pasado que le adviene, remite al profundo convencimiento benjaminiano según el cual la historia es interpretación y sólo puede interpretarla quien no esté conforme con las teorías dominantes, que es quien está pagando el costo de las interpretaciones dominantes.

Queda por saber qué pasado es ese, capaz de hacerse presente inopinadamente, cómo puede informar al sujeto que se busca, qué relación existe y se establece entre ellos. Volveremos a propósito del pasado.

\section{El historicismo}

La otra concepción del tiempo con la que Benjamin polemiza vivamente es el historicismo. ${ }^{17}$

En la Tesis VII Benjamin hace suya la recomendación de Fustel de Coulanges quien aconsejaba a quien quisiera revivir una época pasada olvidarse de la historia que la cuenta, la celebra y la transmite. Ese viaje al pasado valiéndose de las tradiciones y de la cultura sólo denota pereza, acedia: un dejarse llevar que no conduce a ninguna parte y que sólo produce tristeza y frustración en quien espere algo. El hilo conductor que nos lleva desde nuestro interés presente hasta el pasado por el camino de lo transmitido (kempatía») es el hilo que ata a la parte transmitida, que es la de los vencedores de ayer, con la curiosidad presente por el pasado, que es la de los triunfadores. Lo que llamamos cultura es la herencia acumulada y transmitida por los vencedores. Transitar por ella es reproducirla. Eso es el historicismo y, frente a él, lo propio «es pasarle a la historia el cepillo a contrapelon. Esta conocida y repetida imagen benjaminiana se opone a la del "cilindro ronoso que incensamente se pule»; si con ésta se expresa la actitud de sacar brillo a lo existente, con aquélla se da a entender el desinterés por lo que circula y el afán por encontrar algo del origen que nunca bajará por los cauces establecidos. ${ }^{18}$ 
El polémico Benjamin no ahorra crítica al historicismo: un procedimiento basado en la acedia; un fiarse de la cultura ignorando que los bienes culturales son el botín de los vencedores y como en todos los botines, lo que hay de valor es robado a los derrotados; ponerse al paso de los triunfadores; confundir su legítimo interés por la tradición con la reproducción de la barbarie transmitida, etc. Todo eso es el historicismo.

Como se sabe, el historicismo es una reacción contra las grandes construcciones de filosofía de la historia, más empeñadas en juzgar el pasado y dar doctrina sobre el presente que en «conocerle como realmente ha sidon. Los grandes relatos (que es el precipitado lógico de las grandes filosofías de la historia), por otro lado, pierden de vista la realidad, las tradiciones, lo constante a lo largo de los tiempos. De ahí la decidida voluntad del historicismo por hacer ciencia histórica, para conocer la verdad y para que nada se pierda; también, su convencimiento de que es en la continuidad, en la permanencia de lo particular, en la tradición donde se desvela la verdadera naturaleza del tiempo. Eso, precisamente eso, hacer de la historia una ciencia y entenderla como un continuum, eso es lo que indigna a Benjamin del historicismo. Lo que, sin embargo, no debe ocultar un secreto acuerdo en lo que respecta al interés por el pasado, a la crítica del progreso, a la valoración de lo particular.

Sobre el historicismo vuelve en las Tesis XVI y XVII. El historicismo se ha engolfado en un concepto rígido de pasado que está ahí a merced de cualquier postor. Por eso le compara con una prostituta que por dinero está sicmpre dispuesta a alquilar su cartel más significativo: «êrase una vez». El origen está en venta.

En un escrito anterior a las Tesis, ${ }^{19}$ Benjamin identifica las tres líneas maestras del historicismo: universalidad (historia universal), relato y empatía. Tres puntos en los que se ponen de manifiesto «las energías destructoras" del historicismo y que hay que combatir. Veámoslo.

a) Por lo que respecta al concepto de historia universal, la idea de que la tal historia es la suma de la historia de los pueblos le merece a Benjamin el (des)calificativo de "fuga propia de pereza mental». Ni las complejas estructuras sociales ni las oscuras relaciones que las surcan permite ya hablar del espiritu de un pueblo. Ranke se había enfrentado a su contemporáneo Hegel echándole en cara la insignificancia de su Weltgeist, tan abstracto como vacío. En su lugar ponía la particularidad del espiritu de cada pueblo. Cada época posee su propia dignidad e individualidad que le viene de una instancia transhistórica que le soporta: Dios. Mientras que Hegel remitía al final de la historia la reconciliación entre razón y progreso, el historicismo lo ubica en cada momento del tiempo porque el sentido le viene dado por esa instancia transhistórica.

Formalmente está de acuerdo Benjamin con el historicismo: tambien para él la historia se disuelve en imágenes y constelaciones. No 
exísten los grandes relatos. El sentido está pues en el presente particular. Pero les separa su manera de entender ese presente. El historicismo tiene la certeza de contar siempre con el sentido del presente porque Dios no le falla; para Benjamin, es un riesgo. En ambos, sin embargo, el sentido del presente les viene de fuera. Los puntos de encuentro son varios y sólidos. La descalificación benjaminiana del historicismo tiene más de frustración por un planteamiento que ha intuido la esencia del tiempo, pero que no ha sabido sacar las consecuencias, que de oposición frontal.

b) Por lo que respecta al relato Benjamin opone Marx a Ranke, la construcción al relato, situándose él del lado de aquél. Lo propio del historícismo serían sus relatos épicos. Ahora bien, hay que liquidar el elemento épico tal y como lo hizo el autor de El capital. La historia del capital no se revela en relatos épicos sino en el rigor de una ambiciosa teoría que pone de relieve el papel del trabajo bajo el dominio del capital. Ahí se ponen de manifiesto los intereses de la humanidad mucho mejor que en las monumentales historias universales del historicismo. $Y$ es que ues más difícil honrar el recuerdo de los sin-nombre que el de los famosos... La construcción histórica se dedica al recuerdo de los sin-nombres». ${ }^{20}$

Sorprende, sin embargo, que Benjamin identifique relato épico con historicismo cuando el propio Ranke tomaba sus distancias respecto a esas creaciones de la imaginación subjetiva que ponían en peligro el ideal de objetividad, esto es, la descripción del pasado «tal y como ha sido». Claro que es a esa pretensión de objetividad a la que aquí Benjamin llama relato. No le preocupa pues el déficit de objetividad que pueda arrastrar la narración épica, sino la pretensión de objetividad de la ciencia histórica. La tal ciencia es una invención subjetiva.

El error de origen es pensar que los hechos están ahí al alcance de la mano. Quien quiera echar mano de ellos «a ése, los hechos no le alargarán su manon. ${ }^{21}$ Benjamin remite aquí a su teoría del conocimiento histórico: los hechos no se dan indepedientemente de la comprensión. La subjetividad del conocimiento histórico es una condición del propio objeto. Ese desconocimiento es lo que llama Benjamin acedia, «dégoût des choses espirituelles», pereza en conocer las necesidades del sujeto. La palabrería, la molicia, la apatía ocupan el lugar del esfuerzo por romper las resistencias que nos impiden predisponer al agente conocedor.

Hay que señalar, en cualquier caso, que no siempre utiliza Benjamin el término "relato» de una manera tan crítica. Cuando, por ejemplo, contrapone la novela al relato, contrapone una forma épica y egoísta de experiencia a otra colectiva y emancipadora. ${ }^{22}$

c) En el historicismo, la empatía es el mecanismo secreto que relaciona dos momentos tan distantes como el presente y el pasado. Para Benjamin esa comunidad de intereses entre el historiador y la historia es el bastión más peligroso del historicismo. Ese hilo conductor que va del 
presente al pasado es el de los vencedores: «los dominadores de cada momento son los herederos de quienes siempre han ganado en la historia» ${ }^{23} \mathrm{La}$ empalía es un ingenioso invento con el que se benefician los vencedores de ayer y los dominadores de hoy. Si se supedita la posibilidad de conocer el pasado a la empatía, los triunfadores de antaño pueden descansar tranquilos pues gracias a sus herederos siguen ganando batallas; su causa sigue viva y gozando de buena salud. Los dominadores de hoy, por su parte, pueden presentarse ante sus contemporáneos no como tales sino como defensores de la historia, como cultivadores de los valores recibidos, como un momento más en la tradición de todos. El problema es que toda esa cultura que media entre el presente y el pasado es un botín que debe usu existencia no sólo al esfuerzo de los grandes genios que los han creado, sino también a las fatigas sin-nombre de sus contemporáneos» (Tesis VII). Esto impide transitar por la cultura con la buena conciencia que pretenden los defensores de la tradición. En efecto si todo documento de la cultura es también el de la barbarie, una empatía indiscriminada acaba siendo el camino real de la barbarie que así se transmite y se reproduce.

Esta denuncia de la cultura invita a revisar un supuesto ilustrado harto peligroso: identificar al hombre cultivado con quien ha salido de la barbarie, esto es, del estado natural. El culto puede ser un bárbaro. Para evitar la confusión hay que revisar los valores recibidos a la luz de su proceso de producción (los caídos) y teniendo en cuenta la catadura cariz de los sujetos en los que sobrevive (los vencedores). La cultura, como la tradición, difícilmente pueden darse en la transmisión de valores aceptados y recibidos sino que deben ser objeto de creación. De nuevo aparece aquí la oposición entre "reconstrucción» y "construcción». Construir la tradición equivale a interpretar la historia. Tiene necesidad de interpretar la historia quien se siente frustrado en ella. Por eso los dominadores prefieren repetirla y no interpretarla. La interpretacion, faena connatural al lenguaje humano, remite a la necesidad de una mediación (Vermittlung) ya que no nos es posible el conocimiento inmediato; también, a la exigencia de una explanación del contenido (Auslegung) porque el sentido no es dado de una vez para siempre; finalmente es un juicio sobre la realidad presente (Ubersetzung) de la que forma parte ese pasado todavía no conocido. La interpretación es la tarea permanente de quien se siente vivo.

Vemos, por consiguiente, que la polémica de Benjamin con las teorías del progreso y con el hístoricismo tiene como razón mayor el sentido del pasado del que se desentienden las primeras y que en el segundo toma la forma de una entidad muerta, que se ofrece inerte a toda manipulación del presente. Hora es, pues, de entrar a considerar ese pasado que a Walter Benjamin tanto importa. 


\section{El pasado de los vencidos}

¿Qué pasado es ese capaz de provocar la felicidad a unos contemporáneos sumidos en la desesperanza de un destino que no repara en costo humano (teorias del progreso) o condenados a reproducir la miseria (historicismo)?

Se debe tratar de un pasado especial pues se le pide no sólo que desvele la injusticia presente sino que procure felicidad. Más que de una crítica ideológica lo que se exige de este pasado es una virtualidad salvífica.

Benjamin recurre a la imagen de la fotografía para mostrar la naturaleza del pasado en su filosofía de la historia: «si se toma a la historia por un texto, vale entonces para ella lo que un reciente autor decía a propósito de los textos literarios: el pasado deja en ellos imágenes que se pueden comparar a las que quedan fijadas en una placa gracias a una luz muy sensible. Sólo el futuro dispone de un revelador (Entwickler) lo suficientemente potente como para captar la imagen en todos sus detales. Hay partes en Rousseau o Marivaux que remiten a un sentido oculto que sus propios contemporáneos no pudieron descifrar... Leer lo que nunca fue escrito. El lector, en el que aquí hay que pensar, ese es el verdadero historiador». ${ }^{24} \mathrm{El}$ pasado que interesa es el lado inédito de la realidad que sale a la luz en el momento presente.

En esa metáfora quedan reflejadas las características del pasado que se hace presente: la imprevisión con que se presenta; la fugacidad de la constelación espacio-temporal que permite su salida a la superficie, y, sobre todo, la visualización dẹ pasado en una imagen cuya iluminación le viene del presente: «las estructuras más íntimas del pasado sólo se hacen visibles en el presente cuando son actuadas mediante una luz que brota de la vitalidad de la actualidad $\gg .{ }^{25}$ Tan importante como la espontaneidad del pasado que se hace presente inopinadamente es la luz del presente que le permite salir a la superficie. Eso es lo que caracterizaba la visión benjaminiana de la historia.

Queda por clarificar, sin embargo, qué pasado es el que se hace presente y de dónde viene esa luz que permite a la placa fotográfica captar una imagen inédita de una realidad que nos puede resultar familiar de otra manera.

«Der Abfall der Geschichte.» El desecho de la historia. El historiador que es Benjamin, un profeta vuelto hacia atrás, no anda a la búsqueda de lo más valioso, ni le interesa lo más llamativo. Sólo el lumpen, el desecho. ${ }^{26}$ La mirada de quien se dirige a la parte oscura de la realidad puede recibir la luz suficiente para ver lo inédito y desenmascarar así el presente.

Estamos ante una secreta complicidad entre el sujeto histórico, que trata de conocer el pasado, y el objeto del conocimiento, que pugna por hacerse presente. Es más, el indicador de una auténtica filosofía de 
la historia consiste precisamente en que «el auténtico conocimiento de la historia devenga autoconocimiento del sujeto cognoscenten. ${ }^{27} \mathrm{El} \mathrm{momen-}$ to de conocimiento del pasado coincide con el momento de autoconocimiento del sujeto. Eso sólo es posible en el caso de un sujeto necesitado, que se sabe no-sujeto, y que tiene que hacerse con un contenido no existente porque lo existente le sume en la pérdida de subjetividad. A eso llama Benjamin Erfahrung, experiencia. El sabe bien que planteando las cosas así se aleja de las teorías materialistas del conocimiento, incluidas las marxistas, que remiten la verdad al establecimiento de unas relaciones sociales justas, y se aleja igualmente de las entonces brillantes teorías heideggerianas que colocaban la verdad del lado "del reino de las ideas», esto es, al margen de las necesidades del sujeto. Su filosofía de la historia, por el contrario, descansa en una teoria de la experiencia.

El meollo de la cuestión es la relación entre el sujeto y el objeto o, dicho en términos diltheynianos: cómo es posible el conocimiento histórico, habida cuenta de la diferencia entre el presente y el pasado. La respuesta de la hermenéutica clásica: porque entre ellos media la historia. El sujeto es histórico y el objeto, también. El objeto hizo historia y quien hoy le interpreta también quiere hacerla. La historia es la tarea común a la que se deben el pasado y el presente, el historiador y la historia. Ese común empeño explica la invocación de la empatía, de un hilo conductor que liga al presente con el pasado. De ahí la interpretación histórica como un continuum.

Pero de esta suerte la historia se repite, no se hace. Se confunde lo que tiene valor histórico con lo transmitido. Frente a quienes recurren a la empatía para posibilitar el encuentro del presente con el pasado, Benjamin coloca la cita, como figura de secreta reunión entre el pasado y el presente. Como si estuvieran esperándonos los que ya se han ido. ${ }^{28}$ Conviene prestar atención a este cambio de dirección: el historicismo va del presente al pasado, mientras que Benjamin viene del pasado al presente. Este cambio de dirección es algo más que un juego de palabras, pues "mientras la relación del presente con el pasado es meramente temporal, continuadora, la relación del pasado con el ahora es dialéctica: no es un decurso, sino una imagen, algo que nos (a)saltam.29 Veamos.

Cuando se interpreta el pasado desde los intereses del presente, el pasado reproduce la situación dada. Hay entonces una relación de continuidad; la única diferencia sería temporal en el sentido de que lo mismo se produce en dos momentos distintos. Si es el pasado quien se hace presente, la cosa cambia: su presencia es una interrupción de los tiempos que corren. La imágenes de Benjamin se agolpan para mostrar la novedad de su reflexión: habla de interrupción activa (Dialektik im Stillstand), de (a)salto al presente, de parón del tiempo como querían los revolucionarios franceses que disparaban a los relojes de las torres para 
acabar con un tiempo que no era el suyo. Pero sobre todo habla de imagen (Bild): la irrupción del pasado en el presente es una imagen, entendiendo por ello aquello del pasado capaz de conformar creativamente con el presente una nueva constelación de sentido.

La insistencia en la expresión imagen para señalar la fuerza del pasado hay que entenderla en oposición a ciencia. Hay una ciencia del pasado y un pasado que sólo se actualiza en imágenes. El pasado de la ciencia son las huellas que permiten una reconstrucción arqueológica, en todos los sentidos; el pasado de la imagen es un vacío del que sólo la cita y la alegoría pueden decirnos algo.

La cita - «das Zitat»- es un tema recurrente tanto en el Benjamin crítico del arte y de la literatura, como en el filósofo de la historia. La cita no es la confirmación de la opinión del autor mediante el recurso a la autoridad del pasado. Al contrario, la cita es de fragmentos desgastados, desgajados de su contexto habitual y original y que ahora se recuperan para formar parte de un plexo inédito. Cita es la apropiación de la Roma antigua que hizo la Revolución francesa. En esa referencia se libera a Roma de interpretaciones convencionales para transformarla en motivo de un gran acontecimiento. Hay ahí mucho de la cultura surrealista cuya voluntad de hacer extraño lo convencional, de sabotear lo consuetudinario y de revolucionar los valores, tenía por quicio la voluntad de hacer sorprendente lo habitual y habitual lo sorprendente..$^{30}$

La técnica alegórica consiste en dotar de sentido «al mundo profano», es decir, al que no lo tiene. La alegoría se ocupa de naturaleza muerta, de tierra calcinada, de ruinas y miserias. La alegoría tiene esa preferencia por el mundo despreciado de las apariencias. La interpretación alegórica es salvación de la naturaleza muerta. ${ }^{31}$

La cita y la alegoría llegan allí donde la ciencia de la historia no alcanza. El objeto de un conocimiento científico del pasado necesita algo de ser, una huella, una parte de la realidad. La ciencia histórica se basta con eso para reconstruir el resto. $O$, dicho de otra manera, la ciencia histórica vive del principio de causalidad; necesita de un eslabón para remontar la cadena. Todo lo que es efecto es causa; del efecto, a la cau$\mathrm{sa}$, hasta el final que es el presente.

¿Y si hubiera momentos que sólo son efectos, sin haber devenido causa de nada? ¿Y si no hubieran dejado rastro alguno? La historia de los oprimidos - la que interesa a Benjamin - es una cadena de derrotas. Pero con huellas, muchas veces. Se puede hacer una historia cientifica de esas derrotas. Hay otra parte de esa historia, sin embargo, que no ha dejado huellas. No es la historia de los oprimidos que se rebelaron sino la de los oprimidos que o no tuvieron fuerzas para rebelarse o de quienes no queda ni rastro. Primo Levi cuenta cómo los supervivientes de los campos de concentración fueron unos "privilegiados" dentro; de las víctimas-más- 
víctimas no queda rastro. ${ }^{32}$ De ese pasado no puede haber ciencia, sólo representaciones gracias a relatos contados. Que para su filosofía de la historia sea más importante el judío anónimo de Auschwitz que el rebelde Espartaco se explica si tenemos en cuenta lo que en realidad hacemos con los espartacos de la historia: les convertimos en pedestal de la historia, en momentos del progreso actual. Si no hubiera sido por ellos, decimos, no se hubiera eliminado la esclavitud. Por supuesto que ese progreso de la humanidad debe ser valorado generosamente. Pero si simultáneamente no tenemos presente o damos por inexistentes a quienes carecen de relevancia, difícilmente podremos tomar conciencia del peligro que nos amenaza, que nos está amenazando: las muertes anónimas, sin titulares de periódicos, víctimas de una injusticia igualmente anónima. ${ }^{33}$ Benjamin recurre a una expresiva imagen para expresar la radicalidad de su recuerdo: se puede ejemplificar el conocimiento histórico con la imagen de una balanza en uno de cuyos platos colocamos el pasado y en el otro, el conocimiento del presente. Si en éste colocamos pocas ambiciones, en el otro bastará con echar poco peso. ${ }^{34}$ Se necesita tanto más de pasado cuanto mayor sea la ambición del presente. Si está en juego la felicidad de las víctimas anónimas del Tercer Mundo, por ejemplo, habrá que rescatar el sentido de las víctimas anónimas del pasado, para poder entender el peligro de nuestro presente; para salvar a Mandela, sin embargo (dicho sea con todos los respetos), bastaría recordar a Espartaco.

En la glorificación de lo caído y en la resurrección de la naturaleza muerta, la alegoría se erige en el lenguaje de la felicidad.

La cita y la alegoría aluden al modo cómo lo deshecho de la historia se convierte en sentido del presente. Al tener que haberselas con la parte de la realidad que no ha sido abusada, su inesperada presencia turba y vivifica: turba la seguridad de la realidad dominante y da vida a un presente víctima de la acedia.

La relación creativa del pasado con el presente es la substancia del carácter mesiánico del tiempo. El Mesías remite a la plenitud de los tiempos; pues bien, lo importante es entender que esa plenitud no se da al final de los tiempos sino en cada instante. El Mesías pucde llegar en cada instante y su llegada significa interrupción de la historia en curso: «El Mesías interrumpe la historia; el Mesías no llega al final del desarrollom. ${ }^{35}$

Nos preguntábamos qué pasado es ese capaz no sólo de denunciar la injusticia del presente sino de traer la felicidad al presente maldito. Ese pasado mesiánico es «der Abfall der Geschichte».

Pero si lo propio de ese pasado es hacerse presente como una exhalación, sin avisar y por derecho propio, eso no significa que el sujeto actual, "el historiador", tenga que esperar pasivamente su venida. Necesita, como en la metáfora de la fotografía, de una luz especial. "A nosotros", dice la Tesis II, "como a cada generación que nos precedió, nos ha 
sido dada una débil fuerza mesiánica sobre la que el pasado tiene derechos». Si mesiánico es el pasado, mesiánica es la fuerza del sujeto gracias a la cual puede entender sus obligaciones respecto al pasado. Ese denominador común remite a su teoría del conocimiento histórico: en el acto de conocer se funde la creación del objeto del conocimiento con una nueva conciencia del sujeto cognoscente. Sólo un sujeto en busca de sí mismo puede conocer ese pasado oculto. Sólo el ser necesitado buscará un conocimiento desconocido. La conciencia de la infelicidad permite el conocimiento de lo nuevo.

Benjamin habla, en cualquier caso, de una débil fuerza mesiánica. La disponibilidad del sujeto al mensaje del pasado no se la saca el sujeto de la manga, no es una deducción científica, no procede de un análisis científico de la realidad. Benjamin no da muchas más precisiones y se contenta con afirmar que le viene de fuera, «aus fremden Quellen».

Sobre este punto neurálgico del pensamiento benjaminiano - naturaleza de la fuerza mesiánica que exige y posibilita la felicidad individual presente-caben dos interpretaciones, profana una y teológica, la otra.

a) La interpretación profana traduce «fuerza mesiánica dada a cada generación posterior" por un poder humano cultivado en la tradición judía y a la que hay que referirse para poder contar con él. Hay en la tradición judía una manera de experimentar el sufrimiento, unas preguntas sobre el sinsentido de la vida y un negarse al fácil consuelo de los mitos que resulta capaz de fundar hoy una tradición de la esperanza. ${ }^{36}$ Benjamin pretendía liberar esas esperanzas para el desarrollo de la libertad, lanzándolas a la lucha contra aquellas causas, teorías o prejuicios que pretenden acabar con el viento de la historia. En tiempos de absoluto desconsuelo, venía a decir Benjamin, la esperanza es posible porque ésta no nace de análisis científico, ni se prepara desde la fuerza del presente, sino que se hace presente como el Mesías en la apocalíptica judía donde se enseñaba que cada segundo era «la pequeña puerta por la que podía entrar el Mesías». No es que se espere al Mesías ${ }^{37}$ pues la historia es cosa de hombres; de lo que se trata es de apoderarse de una tradición que supo fundar la esperanza cuando parecía imposible. Apropiarse de la tradición religiosa y hacerla universal.

De nuevo aparece aquí la figura benjaminiana del paso de lo esóterico $\mathbf{u}$ oculto a lo exóterico o común. Es una relación compleja pues se tienen que afirmar simultáneamente los momentos de relación y emancipación. Una imagen trata de expresarlo: «mi pensamiento se da a la teología como el secante a la tinta». ${ }^{38}$ Su pensamiento absorbe efectivamente a la teología, pero como buen secante su pensamiento no debe saturarse de teología hasta el punto de que borre el texto escrito. La función del secante es también señalar bien los perfiles del texto. ${ }^{39}$ Ahí quedan señaladas las diferencias entre su pensamiento y la teología, pero 
también la relación. Esos dos momentos dialécticos se resuelven en la pretensión benjaminiana no de hacer teología sino una lectura profana de una cultura religiosa.

El trato heterodoxo pero frecuente de Benjamin con lo religioso ponía nervioso a Adorno para quien Benjamin a veces deambulaba *entre el positivismo y la magian. Y no es que no estuviera por la labor pues también para Adorno en tiempos de desesperación no cabe otra filosofía que la que no renuncie "al punto de vista de la redención", esto es, que no renuncie al derecho a la felicidad individual. ${ }^{40}$ Sólo que esa tarea no podía tomar más que una modalidad negativa: como negación de la realidad irredenta y no ya como paraíso posible de felicidad. Para Benjamin es sin embargo algo más que eso. La religión representa, como en Hegel, la totalidad de la experiencia y el papel de la filosofía es acompañar con lucidez a la existencia humana en el seno de esa experiencia total. La explicación teológica sería hoy un empobrecimiento o visión parcial de la experiencia de la humanidad. Ahora bien, pese a la parcialidad de su interpretación teológica, la religión sigue siendo el único referente de la experiencia total. El papel de la filosofía no es, pues, doblar los contenidos teológicos sino alcanzar la experiencia de la humanidad que en ellos se contienen. ${ }^{41}$ Ese logro sólo es posible si nos apropiamos del talante religioso, siempre dispuesto a entender el presente más allá de las apariencias o certezas científicas: como una puerta por donde puede llegar el Mesías.

b) En la interpretación teológica el Mesías ya ha venido. No es que esté por venir, sino que ha llegado, por eso vivimos tiempos mesiánicos. La esperanza en momentos desesperados nace de un hecho histórico: el hecho de que en un momento determinado del pasado se confirmara la esperanza de los desesperados es lo que funda hoy una nueva esperan$\mathrm{za}^{42} \mathrm{Si}$ el Mesías ya vino vivimos tiempos mesiánicos en el sentido de que la esperanza forma ya parte del tiempo: en la historia está dada la posibilidad de que cada sujeto de la felicidad la encuentre. La diferencia entre una y otra interpretación podemos pues cifrarla en la diferente manera de entender la llegada del Mesías: como espera permanente, en la profana; como venida que ha tenido lugar, en la teológica. Que no sea fácil distinguir entre una y otra -que no sea fácil entender la primera sin referencia a la segunda- es lo que se pone de manifiesto en la conocida polémica entre Benjamin y Horkheimer. ${ }^{43}$

c) El objeto de la polémica no es otro que saber hasta qué punto el recuerdo de los vencidos puede cambiar su suerte. Benjamin habla de la no-cancelación del pasado. Para Horkheimer la injusticia pasada, pasada es y cancelada está. Si nos empeñamos en hablar de no-cancelación del pasado habría que pensar tan sólo en el pasado feliz cuyas consecuencias se pueden perder. Respecto a las injusticias pasadas, sin embargo, 
sólo se las puede tomar por no finiquitadas si traemos a colación el Juicio Final. A lo que Benjamin replica: Horkheimer se empeña en entender la historia como ciencia y no como memoria. La memoria puede hacer algo que la ciencia no puede: abrir expedientes (los de los vencidos) que la ciencia ha archivado y archivar historias (las de los triunfadores) que la ciencia considera en vigor.

Benjamin no tiene inconveniente en reconocer que este planteamiento supone tomarse en serio la figura religiosa del Juicio Final. ${ }^{44} \mathrm{Y}$ se aviene a ello para rebajar las pretensiones dogmáticas de los juicios históricos. La figura procesal del juicio le va a permitir clarificar su insistencia en la vigencia de los derechos de los vencidos. Reflexionemos sobre lo que significa perder una guerra o perder un juicio. Lo primero que salta a la vista es que no significa lo mismo para quien gana que para quien pierde. Para quien gana no hay duda de la actualidad del juicio o de la guerra pasada: el acontecimiento sigue vivo en sus consecuencias para los herederos. Para los perdedores, sin embargo, el juicio o la guerra carece de toda actualidad. El acontecimiento se agotó con la sentencia o la firma de la derrota. Lo que esto demuestra es que nada metafísico impide considerar al pasado como no-cancelado. Lo hacemos sin ningún esfuerzo cuando se trata del pasado de los vencedores. Entonces, ¿por qué no entender el pasado de los vencidos como un acontecimiento del que derivan derechos pendientes, no saldados? Sólo lo impide la creencia de la eternidad del vencedor. Para entender el pensamiento de Benjamin no debemos perder de vista el interés político de su reflexión: cambiar el presente. Ahora bien, mientras el enemigo de antaño siga incuestionado los muertos no descansarán tranquilos, y los vivos andarán expuestos al mismo peligro que las víctimas de antaño (Tesis VI).

Benjamin no ve otra manera de hacer frente a la contundencia de los hechos, avalada por toda una cultura que es ontología del presente, que recurriendo a la figura judía y judeocristiana del Juicio Final. No la explicará, sin embargo, teológicamente en el sentido de reconocer una respuesta positiva a cada víctima del pasado, pero sí filosóficamente en el sentido de reconocer a esas víctima unos derechos pendientes. Se tienen los derechos aunque no se satisfagan. Sin ese reconocimiento no hay manera de fundar su objetivo político: que la historia no siga su curso y no se repita.

Del espíritu y de la letra se desprende que Benjamin pretende una interpretación profana del mesianismo. No es, sin embargo, una interpretación secularizada, como si el contenido de la tradición religiosa puediera verterse totalmente en ella. La verdad no es desvelamiento sino revelación. Volveremos sobre ello. 


\section{La intencionalidad politica de su filosofía de la historia}

Aunque no hayamos cesado de hablar de pasado, se habrá podido ya ver que el tema es el presente. El giro copernicano que Benjamin quiere imprimir a la filosofía de la historia se cifra precisamente, tal y como veíamos al principio de este trabajo, en el primado de la política sobre la historia, esto es, en la urgencia de cambiar el presente.

Adorno gustaba recordar el acuerdo que sellaron Benjamin y él, en 1929, comprometiéndose ambos en un relativismo radical basado en el reconocimiento del presente como mediación necesaria de toda afirmación sobre la verdad o el significado. ${ }^{45} \mathrm{El}$ presente era su problema y esa centralidad cerraba las puertas a toda ontología -incluida la que ontologizaba la historia, como quería Heidegger- y a toda utopía o historia que recurriera al pasado o al futuro para consolidar el presente. El problema era cómo cambiar el presente.

¿Cómo se concreta la oferta política benjaminiana? Esta es una pregunta que incomoda particularmente a los seguidores de Benjamin. Para Adorno el interés político de su amigo era una concesión forzada por el marxista Brecht, lo que convertía a Benjamin en un "compañero de viajew más por fidelidad a una amistad que por coherencia con su propio pensamiento. Hubiera preferido Adomo que Benjamin se atuviera a una visión negativa de la política, como él mismo.

Pero no era Benjamin un hombre de fáciles concesiones teóricas y menos en un punto tan importante como éste. Ilustrativo es a este respecto el trabajo de Habermas sobre la naturaleza de lo político en Benjamin. Me refiero al escrito "Bewusstmachende oder rettende Kritik» ${ }^{46}$ Ahí compara la tesis de Marcuse sobre la crítica de la cultura con la de Benjamin. sobre la crítica del arte. Desde un típico concepto de crítica ideológica Marcuse denuncia el enmascaramiento de la realidad por el arte burgués que al concebirse autonóno respecto a la realidad social lo que hace es transferir la felicidad al mundo de la ficción al tiempo que ignora y encubre la infelicidad real. Marcuse propugna una integración del arte en la vida real, como un momento de la lucha de clases. El objetivo es la creación de unas relaciones sociales justas, acordes con la realidad de las fuerzas productivas operantes. Es una interpretación claramente política.

El punto de vista de Benjamin es diferente. Observa efectivamente la evolución del arte dotado de un "aura" en el clasicismo, que pierde con el Renacimiento por aquello del desencantamiento y que hoy adquiere la forma de una cultura de masas. Observa la evolución y lo que pretende es salvar o conservar un núcleo de verdad siempre amenazado. Critica el constantc culto a la moda - «das Immergleichen am Neuen»- y trata de salvar lo digno o verdadero en cada momento - «das Neue am Immergleichen»- 
Pues bien, la crítica del arte es un paradigma de su filosofía de la historia: frente al peligro de repetir y reproducir lo viejo, lo que importa es salvar lo nuevo de siempre, lo nuevo del pasado. Lo inédito del pasado es su "Jetzt-zeit".

Su "crítica salvadora" salva el sentido y nos salva del enemigo. El enenigo que acecha cada presente impidiendo que aflore la novedad salvadora es «el poderio del destino mítico». "Destino» evoca una condición humana siempre dispuesta o expuesta a conformarse mecánicamente. La subjetividad tiene que luchar contra el destino. Lo original de Benjamin es que el sentido que funda al sujeto está en el mito. La humanidad es el paso de lo oculto del mito («esoterisch») a lo abierto y participado ("exoterischn). Es una faena de profanación. Pero no hasta el punto de que se pierda la alusión al mito porque entonces lo profano se hace mítico. Es lo que ha ocurrido con el progreso. La amenaza del destino mítico es la reproducción del mito, por una profanación excesiva, que impide la revelación de la verdad oculta. La memoria es el momento de la actualización de esa verdad pasada por la presencia del «Jetzt-zeit».

Sólo un planteamiento así puede salvar ese bien escaso llamado sentido que no se fabrica a capricho (por el trabajo) sino que se recibe del mito. Pero ¿cómo puede alterar la realidad del presente? Parece que la crítica del presente dado reivindicando la presencia de ese novum o fuerza inédita que sube del pasado a lo más que puede llegar es a un "grand réfus» del presente, al desgarro anarquista que condena de injusta la realidad presente. Y poco más. Con razón concluye Habermas: «con la crítica salvadora no se llega a la acción políticas. Quien primero lo reconoció fue el propio Benjamin, quien recurrió al materialismo histórico en un desesperado intento de coaligar mesianismo y marxismo para hacer frente a la barbarie nazi. Cuando, por presión de Brecht, acepta la relación entre crítica y política en el sentido de instrumentalización propagandística de la crítica por la lucha de clases, Benjamin da fe del fracaso de su intento. ${ }^{47}$

Reducir la filosofia de la historia de Benjamin a mera garantía de sentido, incapaz, sin embargo, de afectar las estructuras políticas de poder, sería quizá interrumpir demasiado pronto la reflexión. Hemos visto, en efecto, cómo su proclamación del primado de la política sobre la historia se cifraba en su ambicioso tratamiento del presente. Lo que la historia no entendía, tanto en su visión historicista como en la progresista, era la dignidad de los sujetos presentes que no pueden ser precio de ningun bienestar futuro sino que en sí mismos son sujetos de felicidad.

Hoy ya sabemos que el bienestar material puede coexistir con la opresión política. No basta acabar con el hambre para que haya libertad. Es más, ya hemos hecho la experiencia de que el bienestar suele ir acompañado de un déficit de libertad. Esto que lo saben hoy hasta los 
defensores de las teorías del progreso no se decía hace cincuenta años. Benjamin fue pionero en establecer una relación entre bienestar-libertadfelicidad. Pionero, pues, en la "dialéctica de la Ilustración», pero inasimilable por sus defensores actuales. El moderno concepto de emancipación, en efecto, une los de bienestar y libertad. Cuando Habermas entiende que en las modernas y complejas sociedades, emancipación equivale a "conformación participada en las estructuras administrativas de decisión» ${ }^{48}$ está reconociendo una emancipación sin "felicidad", esto es, sin sentido. No es poca cosa, en cualquier caso, reducir el hambre y la opresión política. ¿Por qué descalificarlo en nombre de una carencia de sentido que escapa a la acción política?

Y Benjamin se empeña en desinteresarse por ese tipo de emancipación. Para él progreso correctamente entendido equivale, como decíamos, a bienestar, más libertad, más felicidad. Y lo último es lo primero, de tal suerte que sin felicidad no hay libertad ni bienestar posible para nadie. Es decir, una política que no quede informada por el «Jetzt-zeit» que pone sobre la mesa los derechos no saldados del pasado, no tomará en serio los derechos igualitarios de los marginados y sin ello todo bienestar o mejora democrática es irrelevante.

La intransigencia que de aquí se desprende confirma el anarquismo extremo e inmisericorde de un Benjamin que desprecia cualquier mejora, cualquier reforma. Imaginemos un gobierno mundial de la ONU cuya política económica redujera la miseria en el mundo y cuya política social estableciera gobiernos democráticos en todos los países. Eso sería irrelevante si las decisiones no responden a unas motivaciones de sentido que nos vienen dadas por una determinada experiencia: la memoria passionis o "die erinnerte Erleichterung». A Habermas esto le parece excesivo y por eso trata de salvar a Benjamin del anarquismo ganándole al reformismo: puesto que caminamos hacia una sociedad emancipada sin sentido, que Benjamin esté ahí, en el corazón del reformismo, como aviso permanente de la distancia que media entre la buena vida y la vida buena.

Habermas, en esa interpretación, labora pro domo sua. Como para él la emancipación que nos viene cumple en cualquier caso con la exigencia de participación, no necesita de Benjamin más que el adorno semántico. Benjamin vale como conciencia crítica, no como alternativa política.

La cosa se puede ver, sin embargo, de otra manera: no que se minusvalore la lucha contra el hambre en el mundo sino que la pretendida emancipación participativa nunca se la toma en serio. La crítica a formulas políticas derivadas de una concepción positiva de la universalidad nace de la desconfianza en que así se consiga universalidad alguna. Veamos esto.

La universalidad positiva supone, como la filosofía clásica de la historia, una ontología del presente: una identificación entre verdad y tiem- 
po. Si el citado modelo de un Gobierno Mundial de la ONU vale como concreción de la universalidad positiva podemos imaginar un estado de bienestar mundial regido desde la ONU. ¿Por qué se niega Benjamin a esa sincronía del bienestar y de la libertad? Porque si el presente - ese hipotético presente- es la verdad o la concreción de cualquier otro universal, el pasado es el precio del universal. Ahora bien, con esas premisas lo que se podrá es incrementar el club de los ricos o de los libres, pero nunca será universal porque siempre habrá quien pague el costo del progreso. Si entendemos el hipotético Gobierno Mundial como universalización de los modelos existentes logrados (el sueco o el suizo, por ejemplo), el proceso de universalización reproducirá los vicios del modelo conocido.

Lo discutible no es el gradualismo del modelo sino la reproducción de un modo de progreso que acepta como inevitable la infelicidad de los presentes. Pero, ¿existe algún reformismo capaz de hacer avanzar el bienestar y la libertad sin cobrarse la cuota histórica de la infelicidad de alguien? Sí, podría responderse benjaminianamente, si se entiende la pregunta en el sentido de concebir una política universal basada, no en la extensión del Estado de Bienestar existente, sino en la creación de un orden universal a partir de los derechos de las víctimas del progreso, pasadas y presentes. No es lo mismo ampliar el club de los ricos que los ricos se planteen su política desde los uintereses" de los pobres. Es la diferencia entre una universalidad positiva y otra negativa.

Lo que caracteriza a una universalidad negativa es, en primer lugar, la aceptación del principio de realidad. La realidad es desigual: hay ricos y pobres, dominadores y oprimidos, Norte y Sur, etc. Mantener conceptualmente esa realidad por principio significa renunciar a toda universalidad que haga abstracción de la misma. Si planteamos la verdad o la justicia desde supuestos simétricos (como quiere la "Teoría del discurso" o el jusnaturalismo o cualquier universalización de la dignidad humana etc), hacemos abstracción de la realidad y damos por solucionado el problema político de la desigualdad antes de plantearle. Ni la filosofía ni la política debieran progagar la igualdad abstracta de los hombres, ni siquiera como idea, porque "la utopía abstracta es demasiado compatible con las tendencias más insidiosas de la sociedad».49

Hay que entender, en segundo lugar, la diferencia real interrelacionadamente: hay pobres porque hay ricos. La lucha contra la pobreza supone la alteración substancial del estatus del rico. Un proyecto mundial de distribución justa de las riquezas no consiste en la aplicación de unos cánones de justicia allí donde reina la injusticia cuanto un cuestionamiento de quienes se sienten ya instalados en la justicia. Lo que haría imposible el Gobierno Mundial de la ONU no es que carezca de poder para obligar a los países ricos a invertir en los países pobres, llevar a 
cabo la necesaria transferencia tecnológica, etc., cuanto "obligarles» o convencerles para que planifiquen su presupuesto nacional de acuerdo con los derechos de los países pobres.

Este es el punto neurálgico en el que la cultura política implícita en la filosofía benjaminiana de la historia choca con la de la Modernidad. Para entender la riqueza acumulada - la material y la espiritual- como un botín de los vencedores de ayer dejado en herencia a los dominadores de hoy, para eso hay que haber arreglado las cuentas con filosofías de la historia tanto historicistas como progresistas. Desde esta nueva cultura, el pretendido sujeto es el poseedor de un botín y sólo podrá constituirse en sujeto rehaciendo su relación con el otro, con el no-sujeto. No olvidemos que lo que está en juego no es sólo un problema de justicia, sino de sentido.

La Modemidad, sin embargo, nos ha educado en otra cultura política: que nos constituimos en sujetos sea por decisión propia, por decisión colectiva, cuando no por nacimiento.

Finalmente, lo que de una universalidad negativa deriva no es un Gobierno Mundial sino un nuevo ordenamiento. La experiencia histórica demuestra que la concepción positiva de los universales puede crear una solidaridad nacional pero no transnacional. En el estado moderno se concilian los intereses individuales y los comunitarios, de ahí que los estados más avanzados tiendan a concretar políticas solidarias, pero nacionales. Con otros países puede haber, todo lo más, programas de ayuda.

La concepción nacionalista de la ética política es uno de los supuestos menos discutidos, es decir, más aceptados. Tiene que ver con la universalidad positiva: si el bonum o el verum nacen de la subjetividad, la solidaridad será o una emanación del individuo o un consenso del colectivo. Más bien, un encuentro de ambos dentro de los límites de la comunidad cuyo poder ellos conforman. Desde una universalidad negativa, empero, en la que el pretendido sujeto tiene que definirse desde el no-sujeto, la solidaridad es el acto constituyente de la subjetividad: uno hace propia la causa del otro (del no-sujeto) y en ese momento le adviene el ser sujeto. La intersubjetividad como fundamento de la subjetividad obliga a tener presente al otro a la hora de definirse uno mismo. En eso consiste el nuevo ordenamiento: en una definición de lo propio desde los otros. Los límites nacionales se derrumban ante el testimonio de la historia y de las relaciones internacionales presentes: no hay una sola riqueza colectiva que se haya producido nacionalmente, mucho menos privadamente. La ética política hoy tiene que hacer justicia a la injusticia de la historia.

La debilidad de este planteamiento es que el actor que puede llevarle a cabo no es el mismo que le da sentido. El sentido viene de lo inédito del pasado, pero quienes tendrían que tomárselo en serio son los herede- 
ros de los vencedores. En los epígonos políticos de la Modernidad (liberalismo, socialismo, comunismo) el sujeto político actual encuentra razones suficientes para entender la política como poderio. Tendría que descubrir su impotencia. Se entiende así que Benjamin cifre su papel en términos de "pasar a la historia el cepillo a contrapelo». Difícil faena cuando a lo que nos han enseñado es a sacar brillo a un roñoso rodillo.

\section{NOTAS}

1. Los textos o tesis «Über den Begriff der Geschichte» están editados en diferentes lugares. Aquí nos referimos a la edición Gesammelte Schriften, editados por $\mathbf{R}$. Tiedermann y H. Schweppenhauser, en Francfort, Suhrkamp Verlag, 1972 y ss. El texto se encuentra en el primer volumen (p. 691-707) junto a las variantes que precedieron a la última versión p. 1.223-1.271). Tarnbién existen varias traducciones al castellano. Seguimos, aunque no siempre, la traducción de Jesús Aguirre en W. Benjamin, Discursos intermumpidos (Madrid, Taurus, 1973), 177-191. El resto de las referencias a Benjamin es traducción propia, salvo que se diga lo contrario.

2. Bucks-Morss lleva la relación anamnética al extremo de un Adorno que revisa sus diferencias respecto a Benjamin a favor del amigo para mejor captar su intencionalidad. En Susam Bucks-Morss, Origen de la dialéctica negativa (Siglo XXI, 1981), 334-335.

3. Es lo que plantea el teólogo O. John en el manuscrito :Im Augenblick der Gefahr. Zu einer politischen Theologie nach Auschwitz im Anschluss an Walter Benjamin».

4. W.B. GS, V 1, 490-1.

5. "Für den materialistischen Historiker ist es wichtig, die Konstruktion eines historischen Sachwerhalts aufs strengste von dem zu unterscheiden, was man gewöhnlich seine "Rekonstruktion" nennt. Die "Rekonstruktion" in der Einfühlung ist einschichtig. Die "Konstruktion" setzt die "Destruktion" voraus"( GS, V, 587).

6. Schnädelbach, Geschichtsphilosophie nach Hegel. Die Probleme des Historismus (Munich, 1974), 147.

7. S. Sevilla Segura, "Kant: razón histónica y razón transcendental", en J. Muguerza y R.R. Aramayo (ed.), Kant después de Kant (Madrid, 1989), 244-265.

8. R. Tiedermann, Studien zur Philosophie W. Benjamins (Francfort, Europäische Verlagsanstalt, 1965), 108.

9. Es lo que Adorno expresaba, según Buck-Morss diciendo que «la historia está en la verdad, la verdad no está en la historia», en op. cit., 107. 132.

10. Lutz Niethammer, Posthistoire. Ist die Geschichte zu Ende? (Reinbek, 1989), 130 -

11. Tesis X. «La criatura" es el "Weltkind" (literalmente «infante del mundo"), una polisémica figura literaria que une la inocencia de la infancia al suefio de la emancipación del adulto.

12. Th.W. Adomo, *Fortschritt*, en Stichworte Kritische Modelle 2 (Surhrkamp, Francfort, 1969), 29-50.

13. Era Marx el que decía «Die kapitalischtische Produktionsweise erzeugt mit der Notwendigkeit eines Naturprozesses ihre eigene Negation* (Das Kapital, MEW, 23, 791 y 15 s.).

14. Las citas de este párrafo se refieren a la Tesis XII.

15. GS I, 1.243

16. GS V, 578

17. H. Schnädelbach, op. cit., $20 \mathrm{y}$ ss. Ahí se puede ver lo polisémico del vocablo "historicismo". 
18. En el artículo "Die Grundlagen der Architekturzeichnung" Benjamin compara el diseño arquitectonico "que de alguna manera cepilla a contrapelo, con la mayoria de los historiadores afanados en sacar brillo incesantemente al presente como si de un cilindro roñoso se tratara", en GS III, 653. Es en la Tesis VIII donde escribe a propósito del materialismo histórico: «considera cometido suyo pasarle a la historia el cepillo a contrapelo».

19. GS $1,1.240-1$.

20. GS I, 1.241.

21. GS IV, 317.

22. Benjamin celebra el desarrollo de la técnica en el cíne porque posibilita una universalización de la cultura; también pondera a la prosa porque sabarca lo mesiánico de la historia universal” (GS I, 1.235).

23. GS, I, 1.241 .

24. GS, I, 1.238 .

25. GS, III, 97.

26. "El método de trabajo [se refiere a la obra Passagen]; el "montaje" literario. Nada tengo que decir. No cogeré nada de valioso ni me apropiaré de formulaciones ingeniosas. Sólo el lumpen, el desecho: ni haré inventario de ello, sólo hacerles valer de la única manera posible: usándoles» (GS V, 574).

27. Carta de Benjamin a Max Rychner, del 7.III, citada por R. Konersmann, Walter Benjamins Gegriff der Geschichte (La Haya, Fernuniversität, 1989), 63

28. Tesis II: «existe una cita secreta entre las generaciones pasadas y la nuestra".

29. GS, V, 576-577.

30. «Las citas en mi trabajo son como ladrones de caminos que asaltan violentamente y roban a los paseantes sus convicciones" (GS, IV, 138).

31. GS, I, 1.151.

32. Primo Levi, Los hundidos y los salvados (Barcelona, 1989).

33. Ver O. JOHN, «Im Augenblick der Gefahr», 25.

34. «Jede geschichtliche Erkenntnis lässt sich im Bilde einer Waage, die einsteht, vergengenwärtigen und deren eine Schale mit dem Gewesnen, deren andere mit der Erkenntnis der Gegenwart belastet ist. Während auf der ersten die Tatsachen nicht unscheinbar und nicht zahlreich genug versammelt sein können, dürfen auf der zweiten nur einige wenige schwere, massive Gewichte liegen» (GS, V, 585).

35. GS, I, 1.243.

36. J.B. Metz ha señalado en repetidas ocasiones el carácter antimitológico de la esperanza judía y de su concepción del tiempo; ver, por ejemplo, Theologie gegen Mythologie, Herder Korrespondez, 1988, 187-193 (a éste y otros trabajos dedico un análisis en mi obra Mistica y política [Estella, 1990], 73-107). Es Metz uno de los pensadores alemanes que más temprana e insistenternente se han interesado por Walter Benjamin. Sería equivocado ver en ell una interpretación «teológica" de Benjamin. Metz es, más bien, un télogo que se sitúa dentro de la corriente cultural que alimentó a Benjamin y reflexiona sobre sus mismos problemas. Si la verdad no es "Enthüllung" (desvelamiento) sino "Offenbarung" (revelación) a Metz le interesa que la imagen no se vele por exceso de luz (profana).

37. L. Niethammer, op. cit, 139.

38. GS, I, 1.235 .

39. De la dificultad de entender al escumidizo Benjamin da fe una autor tan agudo como Georg Steiner para quien aBenjamin compara esa teología con un papel secante que a la vez sostiene y amenaza con absorber sus escritosn (Lecturas, obsesiones y otros ensayos, Madrid, 1991, 30). No es lo mismo si el secante es la teología o su pensamiento. El sentido cambia: interpretación teológica, en un caso; profana, en el otro. Benjamin compara su pensamiento al secante.

40. Ver el comentario de Buck-Morss, op. cit., 333.

41. «Así pues la tarea de la filosofía venidera puede concebirse como la de descubrir o crear un concepto de conocimiento que [...] haga posible no sólo la experiencia mecánica 
sino también la experiencia religiosa. No se pretende decir con ello que ha de lograrse el conocimiento de Dios pero sí que ha de hacerse posible su experiencia y la teoria que a êl se refieres (Sobre el programa de la filosofía futura, Caracas, Monte Ávila, 1970), 12-13.

42. Escribe O. John: "nur die Nachricht von einer wirklich in der Vergangenheit erfolgten Befreiung kann von dem resignativen Aufgeben jeder Hoffnung schützens (op. cit., 19). J.R. Capella también parece preferir, al menos en este punto, la interpretación teológica: «el tiempo de espera quedará abolido si el Mesias ha llegado ya» y el Mesías ha llegado en Jesús de Nazareth cuyo es "no seguir la tradición y las Escrituras sino darles su cumplimiento". Cf. "El tiempo mesiánico en el último Benjamin", Mientras Tanto (enero-febrero, 1991), 49. Estimo, sin embargo, que la intención política del mesianismo (es tiempo de obrar y no de esperar), que justamente subraya Capella se explica en el caso de Benjamin por la venida del Mesías y no por haber venido.

43. GS, V, 588-589.

44. «Mir ist immer die Frage wichtig gewesen, wie die merkwürdige Sprachfigur zu verstehen ist: einen Krieg, einen Prozess verlieren. Der Krieg, der Prozess sind ja doch nicht der Einsatz sondern der Akt der Entscheidung über denselben. Ich habe mir das zuletzt so zurechtgelegt: wer den Krieg, den Prozess verliert, für den ist das in dieser Auseinandersetzung umfassta Geschehen wirklich abgeschlossen und somit seiner Parxis verloren; für den Partner, der gewonnen hat, ist das nicht der Fall. Der sieg trägt seine Früchte ganz anders als die Niederlage die Folge eimheimst. Das führt auf das genaue Gegenteil des Ibsensschen Wortes: "Glück wird aus Verlust geboren, ewig ist nur, was verloren" " (GS, II, 1.338).

45. A las charlas de Königstein, en 1929, dedica Buck-Morss merecida atención en op. cit., 121 y ss.

46. En AAVV., Zur Aktualität W. Benjamins (Suhrkamp, Francfort, 1972), 173-225.

47. Ibid, 215.

48. Ibid., 220.

49. Dice Adorno: «El argumento corriente de la tolerancia de que todos los hombres son iguales, es un bumerang. Expónese a la categórica refutación del sentido común, y aún las más rigurosas pruebas antropológicas de que los judíos no constituyen una raza apenas modificarán algo la cuestión frente al caso de los progroms, ya que los totalitarios saben muy bien a quiénes quieren eliminar y a quiénes no... La utopia abstracta sería entonces demasiado fácilmente compatible con taimadas tendencias de la sociedad, ya que precisamente lo que a ésta le viene a medida es que todos los hombres sean iguales entre sí. La sociedad considera todas las diferencias reales o imaginadas como estigmas infamantes que prueban que aún las cosas no han llegado lo bastante lejos, que algo ha quedado suelto todavia dentro de la maquinaria y que, por lo tanto, no está completamente determinado por la totalidad. La técnica del campo de concentración termina haciendo a los condenados lo mismo que a sus guardianes, y a los asesinados asesinos. La sociedad emancipada no habría de ser, por lo tanto, el Estado de la unidad, sino la concretización de lo general en la amonía de las diferencias. La política, a la cual todo ello le concernixía seriamente, no debiera por esto mismo propagar la igualdad abstracta de los hombres ni siquiera como idea... (Minima Moralia, Caracas, Monte Ávila, 1975), 114 (Melange, 64). 